\title{
Nota clínica
}

\section{"Pokemonitis": los peligros de los tatuajes con henna negra}

\author{
E. Maiso Merino ${ }^{a}$, J. Bravo Acuña ${ }^{b}$, M. Merino Moína ${ }^{b}$

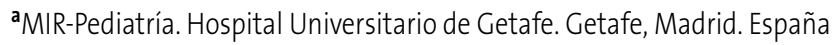 \\ - bediatras. CS El Greco. Getafe, Madrid. España.
}

Publicado en Internet:

27-agosto-2013

Esther Maiso Merino: esther.maiso@gmail.com
Palabras clave:

- Dermatitis de contacto

- Henna

- Parafenilendiamina

- Tatuaje
さั

Los llamados tatuajes temporales realizados con henna negra son cada vez más frecuentes durante los meses de verano, especialmente en niños y jóvenes. La henna es un colorante natural que se utiliza mezclado con otras sustancias, como la parafenilendiamina, que pueden tener capacidad sensibilizante. Se describe el caso de un niño de cuatro años que presentó en ambos antebrazos lesiones residuales hipopigmentadas un mes después de la realización de estos tatuajes. Queremos aprovechar estas imágenes curiosas para llamar la atención sobre los peligros de la henna negra.

\section{"Pokemonitis": the dangers of black henna tattoos}

\begin{tabular}{|c|c|}
\hline 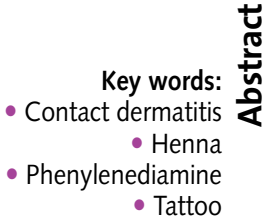 & $\begin{array}{l}\text { The so-called temporary tattoos made with black henna are increasingly common during the sum- } \\
\text { mer months, especially in children and youth. Henna is a natural dye that is used mixed with other } \\
\text { substances, such as phenylenediamine, which may have sensitizing capacity. We describe the case of a } \\
\text { four year old boy who presented residual hypopigmented lesions on both forearms a month after the } \\
\text { completion of these tattoos. We want to bring these curious images to draw attention to the dangers } \\
\text { of black henna. }\end{array}$ \\
\hline
\end{tabular}

\section{INTRODUCCIÓN}

La henna (alheña) es un pigmento natural derivado de la planta Lawsonia inermes, que se adultera con parafenilendiamina (PPD) para obtener la henna negra ${ }^{1,2}$. La henna es un débil sensibilizante y de forma excepcional se han descrito casos de dermatitis de contacto. Pero la capacidad de producir sensibilización en el caso de la PPD es mucho mayor y puede dar lugar a una reacción inflamatoria local con la aparición de pápulas eritematosas, vesículas y ampollas. Su resolución en unas semanas puede dejar lesiones residuales hiper- o hipopigmentadas ${ }^{1-3}$.

\section{CASO CLÍNICO}

Varón de cuatro años de edad sin antecedentes médicos de interés que presenta lesiones hipopigmentadas posinflamatorias residuales que dibu-

Cómo citar este artículo: Maiso Merino E, Bravo Acuña J, Merino Moína M. "Pokemonitis": los peligros de los tatuajes con henna negra. Rev Pediatr Aten Primaria. 2013;15:251-3. 
jan el contorno de uno de estos tatuajes un mes después de su realización, afectando a la superficie de extensión de ambos antebrazos (Figs. 1 y 2). Las lesiones representan a Ash ${ }^{\circledR}$ y Pikachu $^{\circledR}$, los personajes protagonistas de la serie de dibujos animados Pokemon ${ }^{\circledR}$ (Fig. 3).

En las dos semanas previas había consultado en un centro médico de la localidad en la que veraneaba porque presentaba, en la zona del tatuaje, lesiones vesiculoampollosas sobre una base eritematosa, pruriginosas y sin signos de sobreinfección secundaria. Pasado un año, aún se aprecian lesiones residuales con prurito ocasional.

\section{DISCUSIÓN}

La henna es un pigmento natural derivado de la planta Lawsonia inermes, que se adultera con PPD para intensificar el color, acelerar la fijación o aumentar su persistencia ${ }^{1,2}$. Los casos de dermatitis de contacto descritos en la bibliografía son fundamentalmente producidos por la PPD, mientras que la henna es una causa muy infrecuente. Esto, junto a su carácter transitorio, hace que popularmente los tatuajes se consideren inocuos y se esté extendiendo su uso ${ }^{3-6}$.

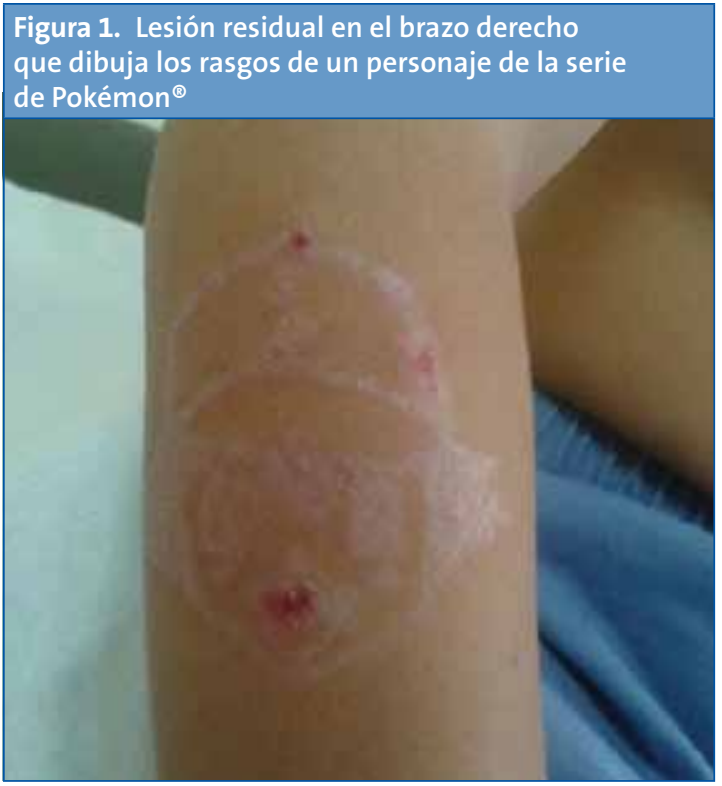

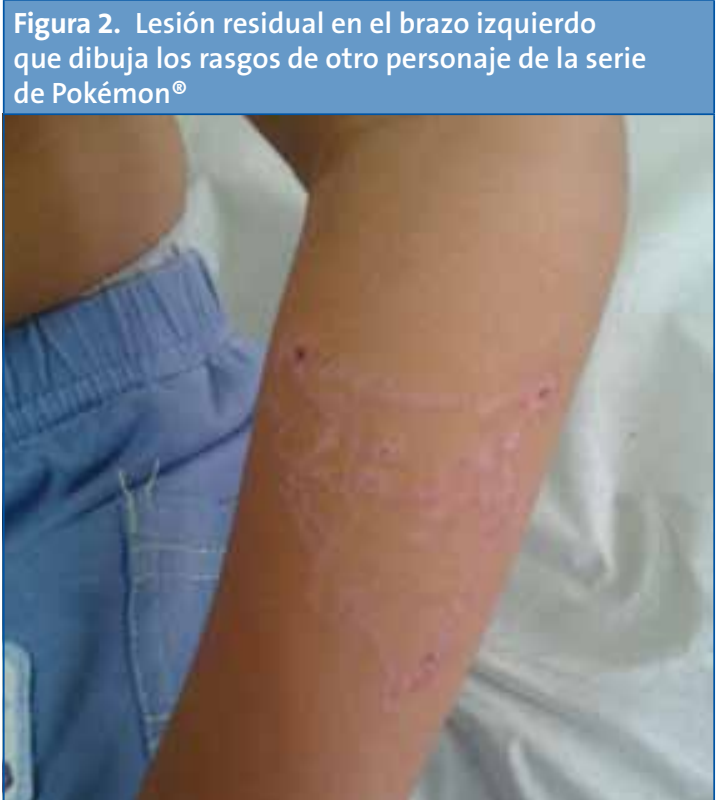

En este caso, la reacción eccematosa ocurrió a la semana de la aplicación del tatuaje, lo que nos sugiere una sensibilización primaria que desencadena una reacción de hipersensibilidad tipo IV. La ausencia de antecedentes dermatológicos y de contacto previo con componentes como la PPD apoya el diagnóstico. En otros casos, la reacción ocurre en un paciente previamente sensibilizado

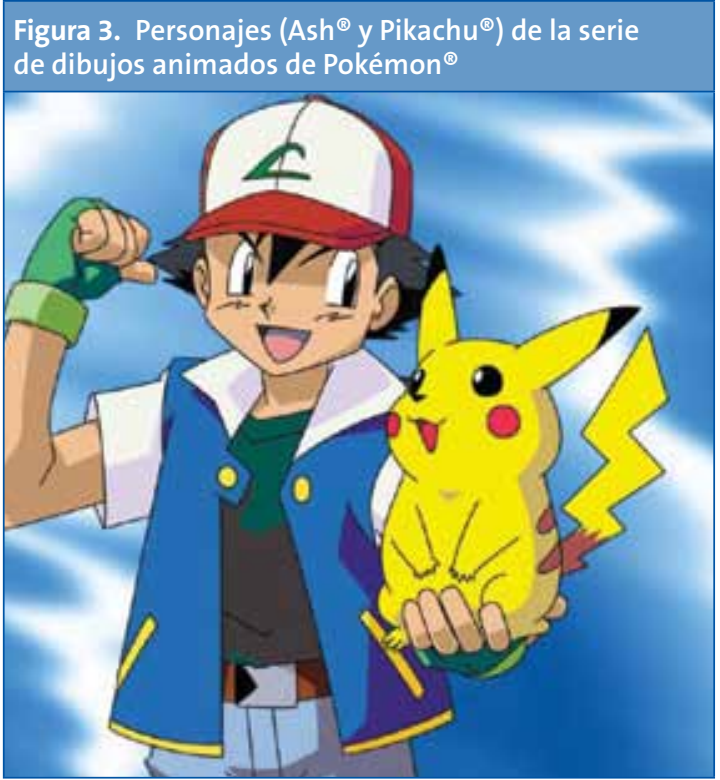


con un intervalo de tiempo más corto ${ }^{4-6}$. Una única exposición suele ser suficiente para producir la sensibilización, ya que la concentración de PPD en estos tatuajes suele ser elevada ${ }^{3}$.

A nivel cutáneo, se produce una reacción inflamatoria con pápulas, vesículas y ampollas, coincidiendo con la localización del tatuaje. En unas semanas evoluciona a una lesión hiper- o hipopigmentada residual ${ }^{1-3}$. También hay casos descritos de reacción liquenoide y erupción generalizada. En las situaciones más graves pueden producirse manifestaciones sistémicas, como edema angioneurótico, insuficiencia respiratoria e insuficiencia renal debida a glomerulonefritis ${ }^{2,7}$.

La sensibilización conlleva otras consecuencias que pueden presentarse a largo plazo, porque la PPD se utiliza como aditivo en la elaboración de otros productos ${ }^{1-3,7}$. Si se realizan pruebas epicutáneas, estas muestran reacción positiva a PPD de tipo ampolloso ${ }^{7}$.

\section{BIBLIOGRAFÍA}

1. Ciriza Barea E, Galardi Andonegui M, García Figueroa B. Reacciones a seudotatuajes de henna. Sensibilización alérgica a parafenilendiamina. An Pediatr (Barc) 2013;78(4):269-70.

2. Lasa EM, Cojocariu Z, Arroabarren E, Echechipía S, Marín MLP, Tabar Al. Tatuaje de henna en niños: ¿natural y temporal? An Sist Sanit Navar. 2007;30(1):1314.

3. Mataix J, Silvestre JF. Reacciones cutáneas adversas por tatuajes y piercings. Revisión. Actas Dermosifiliogr. 2009;100:643-56.

4. Arranz Sánchez DM, Corral de la Calle M, Vidaurrázaga Díaz de Arcaya C, de Lucas Laguna R, Díaz Díaz R. Riesgos de los tatuajes de henna negra. An Pediatr (Barc). 2005;63(5):448-52.

5. Córdoba S, Dorado JM, Sánchez-Pérez J, Vargas E, Alonso A, Fernández-Herrera J. Dermatitis de contac-
Como conclusión, queremos destacar los peligros de esta moda cada vez más extendida entre niños y jóvenes por su aparente reversibilidad. Es necesario conocer las secuelas que puede producir y difundirlas entre la población, desaconsejando su uso, como han hecho recientemente la Asociación Española de Pediatría (AEP) en su página de Facebook $^{8}$ y la Asociación Española de Pediatría de Atención Primaria (AEPap) en su página web Familia y Salud ${ }^{9}$.

\section{CONFLICTO DE INTERESES}

Los autores declaran no presentar conflictos de intereses en relación con la preparación y publicación de este artículo.

\section{ABREVIATURAS}

PPD: parafenilendiamina

to por pseudotatuaje de henna negra. Actas Dermosifiliogr. 2004;95(10):618-21.

6. Miguélez A, Ortiz de Frutos FJ, Polimón I, Comunión A, Iglesias L. Eccema alérgico de contacto por pseudotatuajes. Actas Dermosifiliogr. 2001;92:585-8.

7. Martín JM, Revert A, Alonso V, García L, Molina I, Pereda $C$, et al. Eczema de contacto agudo a parafenilendiamina contenida en tatuajes transitorios con henna. Actas Dermosifiliogr. 2005;96(6):382-5.

8. Asociación Española de Pediatría (AEP). Página web en Facebook. Riesgos de los tatuajes de henna negra [en línea] [consultado el 05/08/2013]. Disponible en http://on.fb.me/14Pqc14

9. Díaz Cirujano Al. Tatuajes con henna negra, ¿qué tengo que saber? Asociación Española de Pediatría de Atención Primaria (AEPap). Familia y Salud [en línea] [consultado el 05/08/2013]. Disponible en www.familiaysalud.es/ 